\title{
Effects of Microwave Irradiation on Nonspecific Protein Binding in the Solid Phase Coated with Bovine Serum Albumin
}

\author{
Seiji KawAGUCHI ${ }^{\dagger}$ and Yuji HIGO \\ Scientific \& Diagnostic Product Development, Scientific Instruments Division, Tosoh Corporation, \\ 2743-1 Hayakawa, Ayase 252-1123, Japan
}

(Received September 17, 2004; Accepted October 29, 2004; Published February 15, 2005)

\begin{abstract}
In solid-phase analytical techniques, a reduction in nonspecific binding at the solid-phase surface is key to obtaining excellent assay performance. We have developed a new preparation method to minimize nonspecific protein binding in the solid phase. Microwave irradiation $(2.45 \mathrm{GHz}, 500 \mathrm{~W})$ was used to produce a highly protein-resistant, dense coating layer of bovine serum albumin (BSA) that was acid-denatured at $\mathrm{pH}$ 4.0. The protein resistance in the BSA-coated magnetic bead was assessed by measuring the enzyme activity of alkaline phosphatase-labeled mouse immunoglobulin G (ALP-IgG) that nonspecifically bound to the surface. In addition, we observed the BSA-coated beads by atomic force microscopy (AFM) and also quantitatively measured the bound BSA, enabling us to propose a model for the denaturation processes caused by microwave irradiation. Compared to conventional BSA-coated beads prepared at $\mathrm{pH} 8.0$ without microwave treatment, the activity of nonspecifically bound ALP-IgG was markedly reduced to $3 \%$. Our results strongly suggest that a meshwork film of extensively associated BSA molecules is formed on the bead surface. This new technique should be useful for the development of polymer supports for use in solid-phase separation analyses, such as heterogeneous immunosorbent assay and column chromatography.

[DOI 10.1295/polymj.37.109]

KEY WORDS Nonspecific Binding / Microwave / Solid Phase / Bovine Serum Albumin (BSA) /

Protein-repellant Capacity /
\end{abstract}

The nonspecific binding of macromolecules to polymer materials is a well-known problem associated with most types of solid-phase assay. In particular, in analytical separation techniques such as heterogeneous immunosorbent assay and column liquid chromatography, a very low nonspecific binding of analytical targets, as well as immunoactive compounds, at the solid-phase surface is essential for high sensitivity, recovery, and precision. ${ }^{1}$ Such nonspecific binding cannot be desorbed completely under common washing conditions. For example, a typical technique for reducing nonspecific binding in solid-phase immunoassays is to block surface spots not covered by immunoactive molecules on the solid-phase material with inert proteins irrelevant to the antigen-antibody reaction, such as bovine serum albumin (BSA), casein, and gelatin. These blocking agents are required to prevent target analytes or immunoactive species from directly interacting with the solid-phase material. ${ }^{2}$ The proteins used as blockers are normally in their native form; in addition, few reports have described techniques for reducing nonspecific protein binding, with the exception of, for example, using heat denaturation with mild temperatures and choosing molecules that are charged at the binding $\mathrm{pH}$. Because solid-phase blocking is generally performed after fixation of the li- gand proteins, which largely have both heat-unstable and $\mathrm{pH}$-dependent biologically active domains, the blocking step requires mild temperatures as well as mid-range $\mathrm{pH}$ values. The nonspecific binding in support surfaces that have been blocked in this way, however, is still not low enough to produce assays with an excellent performance. ${ }^{3}$ To obtain a more proteinresistant surface using simple proteins as blocking agents, we required more stringent measures of denaturation, as well as coating conditions.

The authors recently have tried to use microwave with a frequency of $2.45 \mathrm{GHz}$ as a tool of protein denaturation in order to obtain more protein-resistant and stable BSA film. Many studies concerning the effects of microwaves on protein ${ }^{4-8}$ or water molecules ${ }^{9}$ have been reported. In particular, taking into account their effects on water molecules bound to protein, we expected that an abrupt denaturation of saturatedly bound BSA molecules might lead to a gel formation at the surface concomitant with the production of more protein-resistant interface in the BSA gel. To our knowledge, no work has focused on microwave effects for purposes such as protein-repellant capacity enhancement, much less on the use of microwavetreated proteins for solid-phase analytical supports. 'Nonspecific binding' discussed in this paper means

${ }^{\dagger}$ To whom correspondence should be addressed (E-mail: kawaguti@tosoh.co.jp). 
an irreversible binding of macro protein that cannot be dissociated from the solid-liquid interface of BSAcoated beads even with a nonionic detergent. Therefore, an adsorption-desorption model of protein at a protein-adsorbed surface cannot be adapted, in the present study, to assessment of the nonspecific binding to a stable interface structure of irreversibly denatured BSA films.

In this work, as a preliminary investigation, we examined conditions of both BSA coating and microwave irradiation, in order to evaluate how nonspecific protein binding at the BSA film on solid supports might be reduced. Furthermore, we compared the degree of protein resistance achieved by microwave denaturing methods to that achieved by conductive-heat denaturing methods.

\section{EXPERIMENTAL}

\section{Materials}

Well-characterized magnetic ferrite beads with a diameter of $1.6 \mathrm{~mm}$ in which ethylene-vinyl acetate copolymer (EVA) beads are coated with magnetic ferrite by heat fusion and alkaline phosphatase-labeled mouse immunoglobulin G (ALP-IgG) were supplied by Tosoh (Tokyo, Japan). The ALP-IgG used was prepared by conjugating alkaline phosphatase originating from bovine intestine $\left(M_{\mathrm{w}} 140,000, \mathrm{EC} 3.1 .3 .1\right)$ to mouse immunoglobulin $\mathrm{G}\left(M_{\mathrm{w}} 150,000\right)$ in a $1: 1$ ratio. Bovine serum albumin (BSA, Fraction V) was obtained from Oriental (Osaka, Japan). A protein assay kit (Pierce, Rockford, IL, USA), based on a bicinchoninic acid method, was used for BSA measurements. ${ }^{10}$ Disodium 3-(4-methoxyspiro\{1,2-dioxetane-3,2'-(5'chloro)tricycro[3.3.1.1 $1^{3,7}$ decan $\left.\}-4-y l\right)$ phenyl phosphate (CSPD) solution used as a chemiluminescence substrate for alkaline phosphatase was purchased from Tropix $^{11}$ (Bedford, MA, USA). Three types of polypropylene vessel used for microwave treatment: $2-\mathrm{mL}$ microtubes, $14-\mathrm{mL}$ round-bottom tubes, and $300-\mathrm{mL}$ beakers were purchased from Eppendorf (Hamburg, Germany), Becton Dickinson (Franklin Lakes, NJ, USA), and Sanplatec (Osaka, Japan), respectively. The chemiluminescence signal generated from enzyme reactions was measured with a Lumat LB9501 chemiluminescence detector from Berthold Japan (Tokyo, Japan). For microwave treatment, a general purpose kitchen microwave oven (Model MR-M25) with the highest output of $500 \mathrm{~W}$ and a working frequency of $2.45 \mathrm{GHz}$ was purchased from Hitachi (Tokyo, Japan). BSA-coated magnetic beads were imaged using a NanoScopeVa from Digital Instruments (Santa Barbara, CA, USA) after pretreatment with a Dynac static eliminator PB160M from Fisa (Tokyo, Japan). All other reagents were obtained from com- mercial sources and were of the highest purity commercially available.

\section{Methods}

Preparation of BSA-coated Beads. Beads were prepared by the following as a reference method. The binding of BSA was carried out under static conditions by exposing about 1000 magnetic beads to a $10-\mathrm{mL}$ portion of protein solution in a capped 14$\mathrm{mL}$ polypropylene tube for over $24 \mathrm{~h}$ at $4{ }^{\circ} \mathrm{C}$. The BSA-coated beads were stored in the same buffer. The protein solutions used were $0.1 \mathrm{M}$ phosphate buffer containing $0.5 \% \mathrm{BSA}$ and $0.1 \%$ sodium azide for $\mathrm{pH}$ values ranging from 3.0 to 7.5 , and $0.1 \mathrm{M}$ Tris$\mathrm{HCl}$ buffer containing $0.5 \% \mathrm{BSA}$ and $0.1 \%$ sodium azide for those ranging from 8.0 to 11.2.

Preparation of Beads Coated with Microwavetreated BSA. Beads were prepared by one of the following two methods. In method M-1, three BSA-coated beads were removed from storage and added to a 2$\mathrm{mL}$ polypropylene microtube with $200 \mu \mathrm{L}$ of the same buffer. Microwaves were then applied to the beads through the microtube for $30 \mathrm{~s}$ using the microwave oven on maximum power with the uncapped tube kept in a freezing container filled with ice water, after preliminarily cooling in ice water for $30 \mathrm{~min}$. The tube was then capped and transferred to a temperature-controlled incubator at $37 \pm 0.5^{\circ} \mathrm{C}$ for $6 \mathrm{~h}$ with mixing by a microtube mixer. In method M-2, a $10-\mathrm{mL}$ portion of protein solution was added to a 14-mL polypropylene tube. Microwaves were then applied to the solution through the tube for $30 \mathrm{~s}$ using the microwave oven on maximum power with the uncapped tube kept in a $300-\mathrm{mL}$ polypropylene beaker filled with ice water, after preliminarily cooling in ice water for $30 \mathrm{~min}$. Subsequently, about 1000 beads were added to the protein solution, which was then allowed to stand for more than $24 \mathrm{~h}$ at $4{ }^{\circ} \mathrm{C}$ after gentle mixing by turning the tube upside down.

Protein-repellant Capacity Assessment on Surfaces of BSA-coated Beads. Three beads were placed in a 2-mL polypropylene microtube and the residual protein solution was completely removed by an aspirator. The beads were washed twice with $1 \mathrm{~mL}$ of the same buffer, and then $100 \mu \mathrm{L}$ of ALP-IgG solution diluted to $3.7 \mu \mathrm{g} / \mathrm{mL}$ with $0.1 \mathrm{M}$ phosphate buffer containing $0.1 \% \mathrm{BSA}, \mathrm{pH} 7.4$ was added to the beads and mixed vigorously for $10 \mathrm{~min}$ with a microtube mixer at $37^{\circ} \mathrm{C}$. The ALP-IgG solution was sucked off and the beads were washed three times for $1 \mathrm{~min}$ each by dipping into three separate volumes of $1 \mathrm{~mL}$ of $0.01 \mathrm{M}$ succinic acid containing $0.1 \mathrm{M}$ sodium chloride, $0.044 \%$ Tween 20, 0.011\% Triton X-100, and $0.03 \%$ ProClin $300, \mathrm{pH} 5.8$. The washed beads were transferred to a $75 \times 12 \mathrm{~mm}$ I.D. glass tube and $100 \mu \mathrm{L}$ of $0.2 \mathrm{mM}$ 
CSPD solution was added. The chemiluminescence, expressed as relative light units (RLU), was counted immediately for $20 \mathrm{~s}$ and then recorded.

Quantitative Measurement for BSA Coated on Beads. Five BSA-adsorbed beads were added to a 2-mL microtube. The beads were carefully rinsed three times for $1 \mathrm{~min}$ each by dipping into three separate volumes of $1 \mathrm{~mL}$ of saline, and transferred to a $75 \times 12 \mathrm{~mm}$ I.D. glass tube. Next, a $1-\mathrm{mL}$ aliquot of the working reagent of the protein assay kit was added to the beads and the tube was incubated for $60 \mathrm{~min}$ at $60^{\circ} \mathrm{C}$ in a water bath. After cooling to room temperature, the absorbance of the soluble purple complex formed in this reaction was measured at $562 \mathrm{~nm}$, versus a blank obtained from beads with no bound BSA. The concentration of unknowns was determined from a standard curve.

Sample Preparation for AFM. One BSA-coated bead from the stock solution of beads was added to a 2-mL microtube. The bead was carefully rinsed three times for $1 \mathrm{~min}$ each by dipping into three separate volumes of $1 \mathrm{~mL}$ of $0.1 \mathrm{M}$ Tris- $\mathrm{HCl}$ buffer containing $0.1 \%$ sodium azide, $\mathrm{pH} 8.0$, and then allowed to dry in air. The static electricity of the bead surface was removed with a static eliminator prior to measurement. To fix the bead for measurement, a drop of white-out was placed on a slide and the bead was positioned on top.

Preparation of Beads Coated with Thermally Denatured BSA. Beads were prepared by one of the following two methods. In method $\mathrm{H}-1$, three beads were carefully picked from the beads stored in $0.1 \mathrm{M}$ Tris$\mathrm{HCl}$ buffer containing $0.5 \% \mathrm{BSA}$ and $0.1 \%$ sodium azide, $\mathrm{pH} 8.0$, and added to a $2-\mathrm{mL}$ size microtube with $200 \mu \mathrm{L}$ of the same buffer. The beads in buffer were heated to the desired temperatures in a water bath for $30 \mathrm{~min}$ and then cooled immediately in ice water. In method $\mathrm{H}-2$, a $10-\mathrm{mL}$ portion of $0.1 \mathrm{M}$ Tris- $\mathrm{HCl}$ buffer containing $0.5 \%$ BSA and $0.1 \%$ sodium azide, $\mathrm{pH} 8.0$, was added to a capped $14-\mathrm{mL}$ polypropylene tube, which was heated to the same temperatures as in method $\mathrm{H}-1$ in a water bath for $30 \mathrm{~min}$ and then cooled immediately in ice water. Subsequently, about 1000 beads were added to the protein solution and allowed to stand for more than $24 \mathrm{~h}$ at $4{ }^{\circ} \mathrm{C}$ after gentle mixing by turning the tube upside down.

\section{RESULTS AND DISCUSSION}

\section{Microwave Irradiation Conditions}

We assessed the relationship between the length of microwave irradiation and the protein-repellant capacity at the bead surface, while varying the $\mathrm{pH}$ values of protein solution between $\mathrm{pH} 4.0,6.0$, and 8.0,

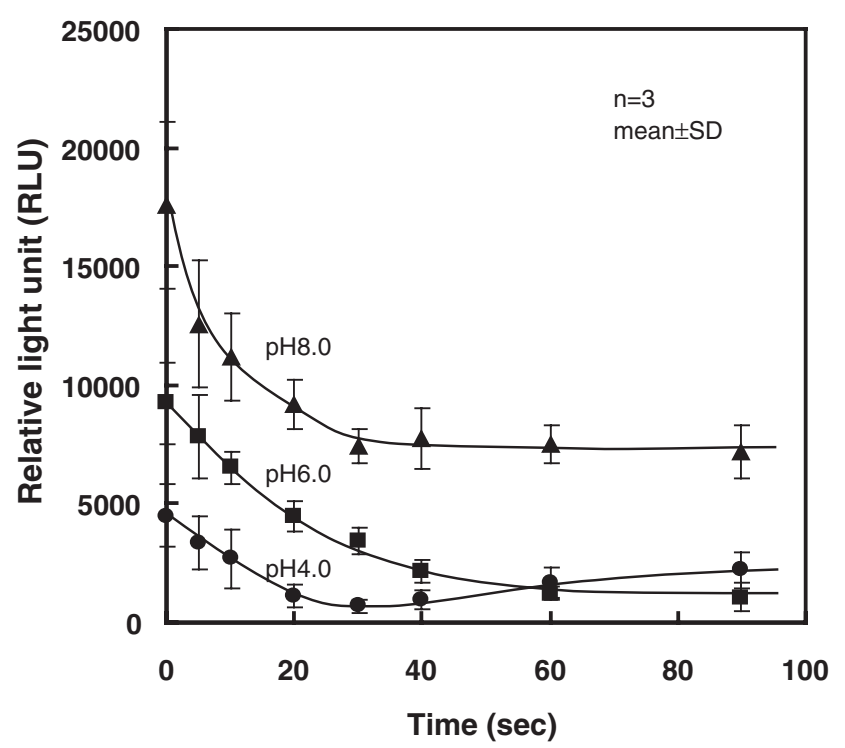

Figure 1. Effects of the length of microwave treatment on nonspecific binding behavior.

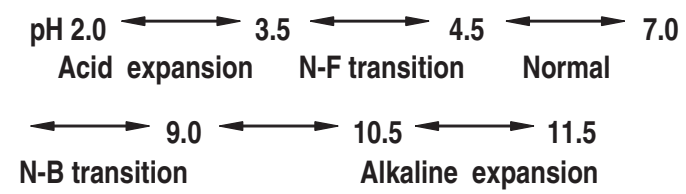

Figure 2. pH-Dependent conformational change of serum albumin. The abbreviations of N, F, and B mean normal, fast, and basic, respectively.

in blocking processes based on the microwave treatment of beads saturated with BSA (Figure 1). RLU values show alkaline phosphatase activity corresponding to the amount of nonspecifically bound ALP-IgG. The resultant patterns for the amount of nonspecific binding of ALP-IgG are shown as three different curves for the three respective $\mathrm{pH}$ values. It was found that the amount of bound ALP-IgG decreased to a plateau in the irradiation time range of $30-90 \mathrm{~s}$ at $\mathrm{pH} 8.0$, decreased gradually until $90 \mathrm{~s}$ at $\mathrm{pH} 6.0$, and decreased to a minimum at $30 \mathrm{~s}$ followed by a slight increase until $90 \mathrm{~s}$ at $\mathrm{pH}$ 4.0. In the case of BSA molecules, reversible conformational changes are known to occur readily with changes in $\mathrm{pH}$ (Figure 2). ${ }^{12}$ In the normal $(\mathrm{N})$ form of BSA, about half of the carboxylic groups of amino acid side chains form ionic bonds with positively charged amino acid side chains, resulting in the formation of ionic interfaces inside the protein molecule. However, these interfaces are reported to be dissociated in the fast $(\mathrm{F})$ form. Because they are exposed on the protein surface, these dissociated side chains are likely to form new hydrophilic interfaces, followed by binding to water molecules in solvent. This suggests that the number of bound waters is markedly increased when BSA is converted from the 
$\mathrm{N}$ to the $\mathrm{F}$ form. At $\mathrm{pH} 4.0$, the point at which BSA is converted to the $\mathrm{F}$ form, the amount of bound ALPIgG before microwave treatment was lower than at the other two pHs. Microwave treatment further reduced the amount of bound ALP-IgG at $\mathrm{pH} 4.0$, as well as at both $\mathrm{pH} 6.0$ and 8.0. The protein-repellant capacity at the BSA surface was defined as the activity of alkaline phosphatase measured in ALP-IgG probe molecules nonspecifically bound to the surface of BSA attached to the magnetic beads. The nonspecific binding of ALP-IgG is thought to be largely due to the interaction between hydrophobic crystallizable fragment $(\mathrm{Fc})$ regions in IgG molecules ${ }^{13}$ and hydrophobic regions located on loops in the BSA molecules. Consequently, RLU values are supposed to be inversely proportional to the degree of protein-repellant capacity in BSA molecule surfaces. The experimental condition of microwave treatment for $30 \mathrm{~s}$ gave rise to the minimum amount of bound ALP-IgG at $\mathrm{pH} 4.0$ and to the smallest variation in RLU values over the whole range of the three $\mathrm{pH}$ values tested. Thus, we employed the 30-s-treatment irrespectively of $\mathrm{pH}$ values in subsequent experiments.

\section{Characteristics in Beads Bound with Micowave-treat- ed BSA}

Figure 3 shows the relationship between the amount of ALP-IgG nonspecifically bound onto the BSA-coated beads versus the $\mathrm{pH}$ values in BSA coating. We compared the degree of the protein-repellant capacity of BSA-coated beads surface prepared by three different coating techniques over a wide range of $\mathrm{pH}$ values from 3.0 to 11.2. The $\mathrm{pH}$ values examined were chosen to cover the region giving rise to acid- or base-induced conformational changes in BSA molecules, in order to test the idea that the protein-repellant capacity in BSA molecular surface may be largely dependent of changes in $\mathrm{pH}$.

For beads prepared by the reference method, those coated at $\mathrm{pH} 3.0$ exhibited the highest protein-repellant capacity of all of the $\mathrm{pH}$ values; in addition, the amount of bound ALP-IgG changed markedly in $\mathrm{pH}$ regions of $\mathrm{pH} 4.0-4.5$ and $\mathrm{pH}$ 6.5-7.5. These $\mathrm{pH}$ regions were considered to be mostly in agreement with those inducing normal-fast $(\mathrm{N}-\mathrm{F})(\mathrm{pH} 3.5-4.5)$ and normal-basic (N-B) (pH 7.0-9.0) transition, respectively. Beads prepared by method $\mathrm{M}-1$ at $\mathrm{pH} 4.0$ had the highest protein-repellant capacity ( $c a .600$ RLU) of the three methods over the whole $\mathrm{pH}$ range examined. From these results, a preparation technique consisting of a saturating step at $4{ }^{\circ} \mathrm{C}$ with BSA solution at $\mathrm{pH} 4.0$, followed by microwave treatment for $30 \mathrm{~s}$, was found to produce the most protein-resistant BSA-coated bead surface ( $c a .600$ RLU). The amount of bound ALP-IgG at the surface was dramatically

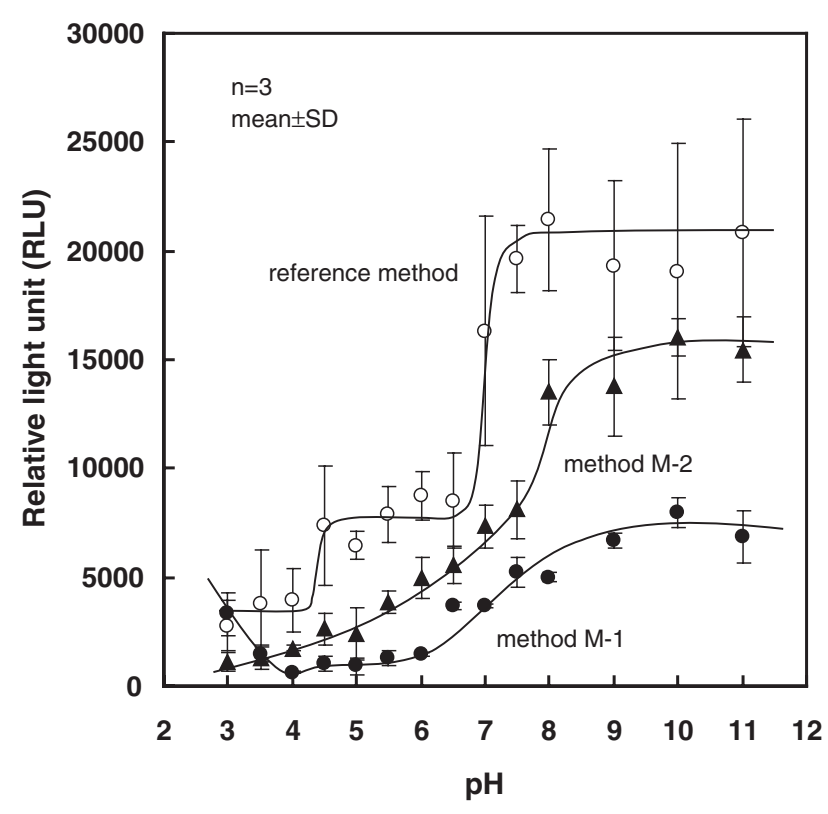

Figure 3. Dependence of nonspecific binding behavior on microwave treatment over a wide range of blocking $\mathrm{pH}$. (1) Reference method (open circles); standard blocking for over $24 \mathrm{~h}$ at $4{ }^{\circ}$ C. (2) Method M-1 (closed circles); microwave treatment of BSA-coated beads for $30 \mathrm{~s}$ before an incubation for $6 \mathrm{~h}$ at $37^{\circ} \mathrm{C}$. (3) Method M-2 (closed triangles); blocking for over $24 \mathrm{~h}$ at $4{ }^{\circ} \mathrm{C}$ with BSA solution pretreated with microwaves.

reduced to about $3 \%$ of that bound on beads prepared by the conventional technique (reference method, i.e., $\mathrm{pH} 8.0,4^{\circ} \mathrm{C}$, and no microwave treatment, $c a .22000$ RLU). Moreover, the inter-assay standard deviations of the amount of bound ALP-IgG by beads prepared by method M-1 were also found to be markedly lower over the whole $\mathrm{pH}$ range as compared with the two other methods.

To improve the protein-repellant capacity in the BSA-coated bead surfaces, it is important to raise both the protein resistance in BSA molecular surface and the coating rate on the beads surface by investigating a combination of unfolding determinants, such as binding to support, change in $\mathrm{pH}$ value, and microwave treatment. The conformational changes in BSA molecules caused by changes in $\mathrm{pH}$ are reversible in solution. Once the BSA molecules are physically immobilized at either acid or alkaline $\mathrm{pH}$, however, they are not thought to refold completely to their native forms, even during the 10-min mixing step with ALP-IgG solution at $\mathrm{pH}$ 7.4. In other words, the conformation formed at the coating $\mathrm{pH}$ is supposed to be partially conserved on the bead, even when the $\mathrm{pH}$ of the medium is changed to neutral.

\section{Amount of Bound BSA}

In order to assess the relationship between the protein-repellant capacity and the amount of bound BSA, 


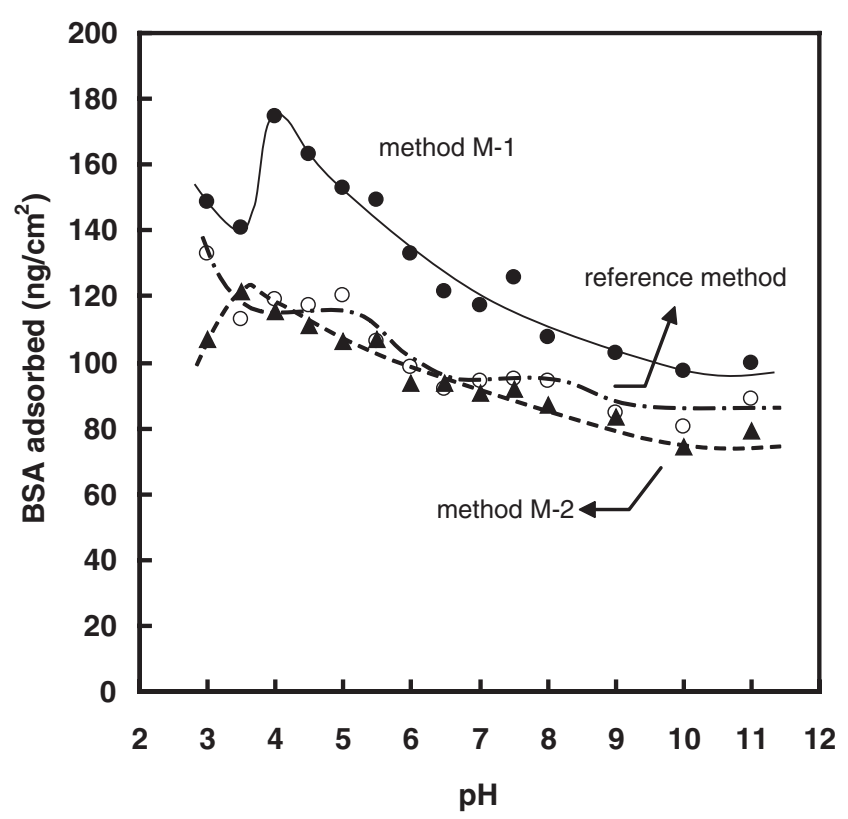

Figure 4. Effects of microwave treatment on the amount of bound BSA. Symbols are the same as in Figure 3. Data are the mean values of duplicate experiments.

the amount of BSA coated on beads prepared by the three different methods was directly measured (Figure 4). The adsorbability of BSA onto ferrite beads prepared by the reference method showed a similar tendency to that onto polystyrene latex reported by Shirahama and Suzawa, ${ }^{14}$ with the exception of the value at $\mathrm{pH}$ 3.0. Beads prepared by method M-1 showed a higher amount of bound BSA over the whole range of $\mathrm{pH}$ values measured than did beads prepared by the two other methods. Beads prepared by method M-1 at $\mathrm{pH} 4.0$ had the largest amount of bound BSA $\left(174 \mathrm{ng} / \mathrm{cm}^{2}\right)$, which corresponds to the $\mathrm{pH}$ value giving the highest protein-repellant capacity. Next, the amount of bound BSA was followed for a time course of $10 \mathrm{~h}$ starting from the end of the microwave irradiation to the bead coated with BSA at pH 4.0 (the same microwave treatment as in method $\mathrm{M}-1$ ) in order to determine whether microwave treatment affected the amount of bound BSA over time (Figure 5). Figure 5 shows that the binding increased with incubation time. The amount of bound BSA per unit surface was increased by $52 \%$, that is, from 115 to $175 \mathrm{ng} / \mathrm{cm}^{2}$ when the adsorbed beads were treated with microwave irradiation, followed by incubation for $6 \mathrm{~h}$ at $37^{\circ} \mathrm{C}$. Incubation for $6 \mathrm{~h}$ without microwave treatment was shown to give a $27 \%$ increase $(146 \mathrm{ng} /$ $\mathrm{cm}^{2}$ ); thus, a $25 \%$ increase (from the subtraction of $27 \%$ from 52\%) was found to be due to newly adsorbed BSA resulting from treating the coated beads with microwave irradiation before incubation.

The coating of BSA depends not only on the $\mathrm{pH}$ and ionic strength, but also on the characteristics of

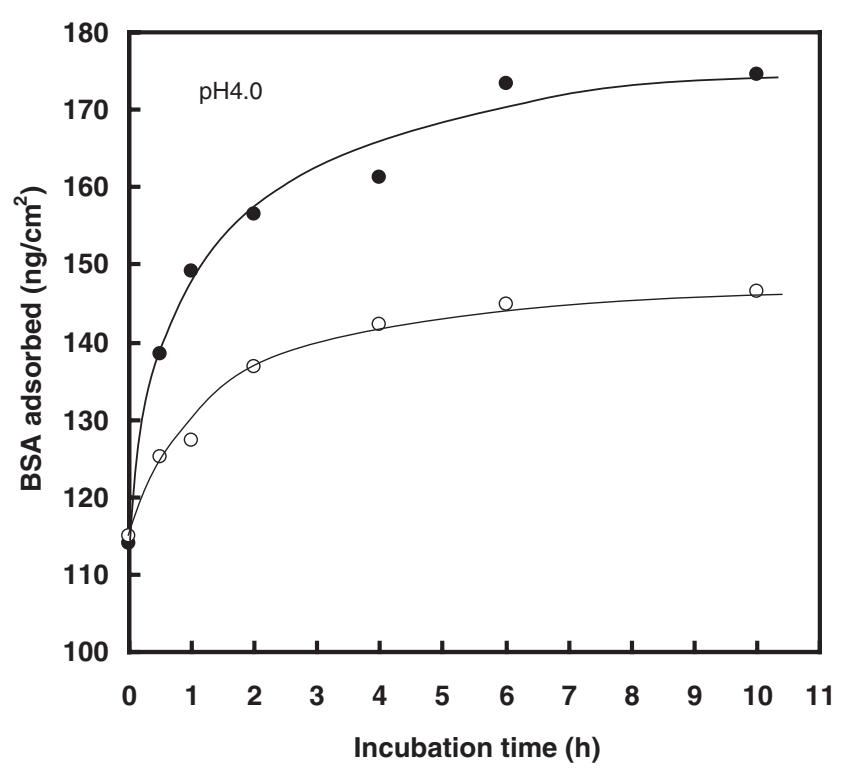

Figure 5. Effects of incubation time on the amount of bound BSA. Conditions: with microwave treatment (closed circles) and without microwave treatment (open circles) before an incubation at $37^{\circ} \mathrm{C}$. Data are the mean values of duplicate experiments.

the solid-phase surface and the denaturation state of the BSA molecules. In this study, the variations in the amount of bound BSA were likely to be determined mainly by denaturation states caused by two different types of microwave treatment at a wide range of measured $\mathrm{pH}$ values. No significant change in the amount of bound BSA was found immediately before and after microwave irradiation, suggesting that microwave treatment does not develop the association between bound BSA molecules and those in the solution, and also suggesting that BSA molecules that are already bound are not desorbed from the beads by microwave irradiation.

\section{Bound BSA Images with AFM}

Figure 6 shows AFM phase images of BSA coated on the magnetic bead surfaces. The magnetic bead surface was found to have an average roughness of $52 \mathrm{~nm}$ in images with a $2-\mu \mathrm{m}$ scan height, due to the exposure of ferrite crystals on the EVA surfaces. Therefore, the resolution in the height images was not sufficient to observe the details of the bead surface, but these are more clearly observed in phase images, where the topography of the EVA is removed. ${ }^{15}$ The typical pattern of bound BSA was observed as very dark contrast regions on the apparent EVA surface as compared to regions on ferrite surfaces. Bound BSA molecules without microwave treatment showed spot-like regions of dark contrast, with a wide range of diameter (from 10 to $50 \mathrm{~nm}$ ) and distance between spots (from 1 to $50 \mathrm{~nm}$ ). The size of these spots is in agreement with a magnitude of BSA ranging from a 

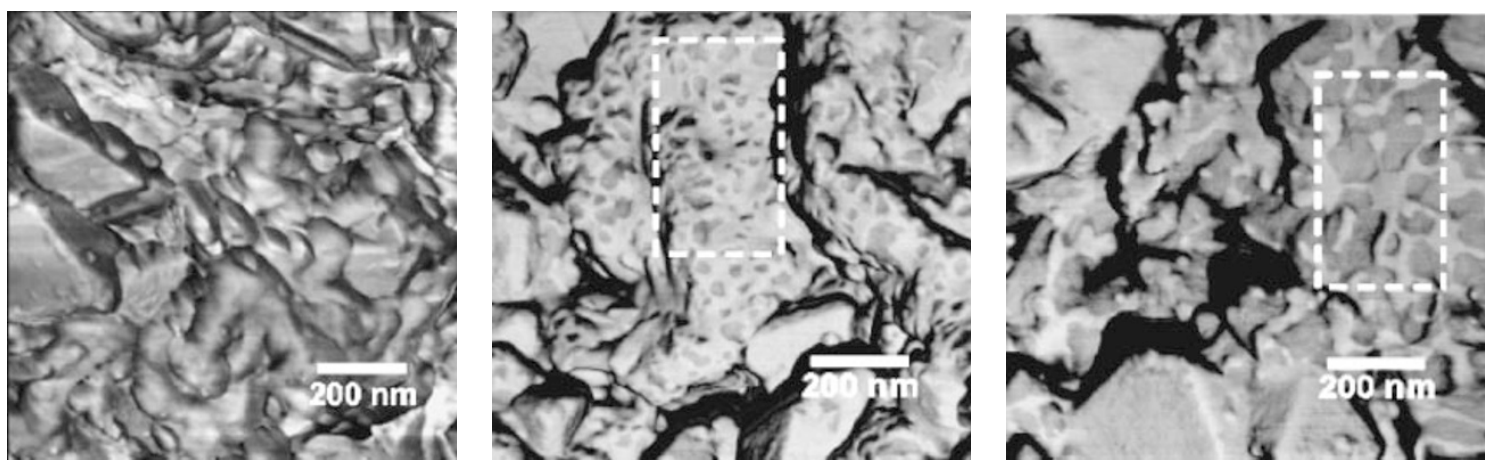

Figure 6. Comparison between AFM phase images of the BSA-coated magnetic bead surface with (right) and without (middle) microwave treatment. The image from the naked magnetic bead (left) is shown as the reference surface. Analytical conditions: scan size, $1.000 \mu \mathrm{m}$; scan rate, $0.6634 \mathrm{~Hz}$; number of samples, 512; data scale, $180.0^{\circ}$. The areas indicated by the boxes show typical spots most probably caused by BSA molecules bound onto the EVA surface.

single to several molecules. ${ }^{16}$

On the other hand, beads that had been treated with microwave irradiation showed images of expanded dapples with diameters ranging $10-500 \mathrm{~nm}$ that were closely located and some of which were interconnecting. From the results shown in Figure 5, the amount of BSA coated after microwave treatment was $25 \%$ more than that coated before treatment; however, the total dark contrast area observed in images of the microwave-treated beads was several times greater than that in images of the non-microwave-treated beads. On the polymer material surface, characteristic topographical features are of the same magnitude as the protein molecules; thus, proteins cannot be distinguished on the surface using topographic images. Phase images can usually provide clearer data, including general protein sizes, than height images when surfaces with a roughness of $10-1000 \mathrm{~nm}$ are being tracked. The more physical properties that are soft, the more that the contrast is imaged darkly. This contrast appears to be due to the difference in physical properties between the bead surface and BSA molecules, such as cohesion or bound water distribution.

In phase images, we cannot obtain height information about the BSA films, however, in the present study it is not important to clarify whether the BSA film is formed in monolayer or not. What is important is to obtain the area information of the interface between the outside of the BSA film and surrounding solution. The AFM phase images provided us valuable data in which it is shown that the area coated with microwave-treated BSA films increased. As mentioned above, microwave irradiation significantly increased the dark contrast area in the AFM images, whereas the amount of bound BSA was only slightly increased. The increase in contrast therefore seems to be due to the widespread association between markedly-expanded bound BSA molecules.
Characteristics in Beads Coated with Thermally Denatured BSA

We compared protein-repellant capacity in microwave-irradiated BSA with that in BSA treated with conductive heat. The nonspecific binding of ALP$\mathrm{IgG}$ and the amount of BSA coated on beads prepared by two methods $\mathrm{H}-1$ and $\mathrm{H}-2$ (see Experimental section) of conductive heating ranging from 4 to $85^{\circ} \mathrm{C}$ are shown in Figures 7 and 8, respectively. The amount of nonspecifically bound ALP-IgG decreased with increasing temperature until 65 and $75^{\circ} \mathrm{C}$ for both methods $\mathrm{H}-1$ and $\mathrm{H}-2$, giving a minimum value of $c a .1000 \mathrm{RLU}$ at $65^{\circ} \mathrm{C}$ and $c a .5000 \mathrm{RLU}$ at $75^{\circ} \mathrm{C}$, respectively. At $65^{\circ} \mathrm{C}$, method $\mathrm{H}-1$ gave the lowest nonspecific binding ( $c a .1000 \mathrm{RLU}$ ) of the two methods over the whole temperature range exam-

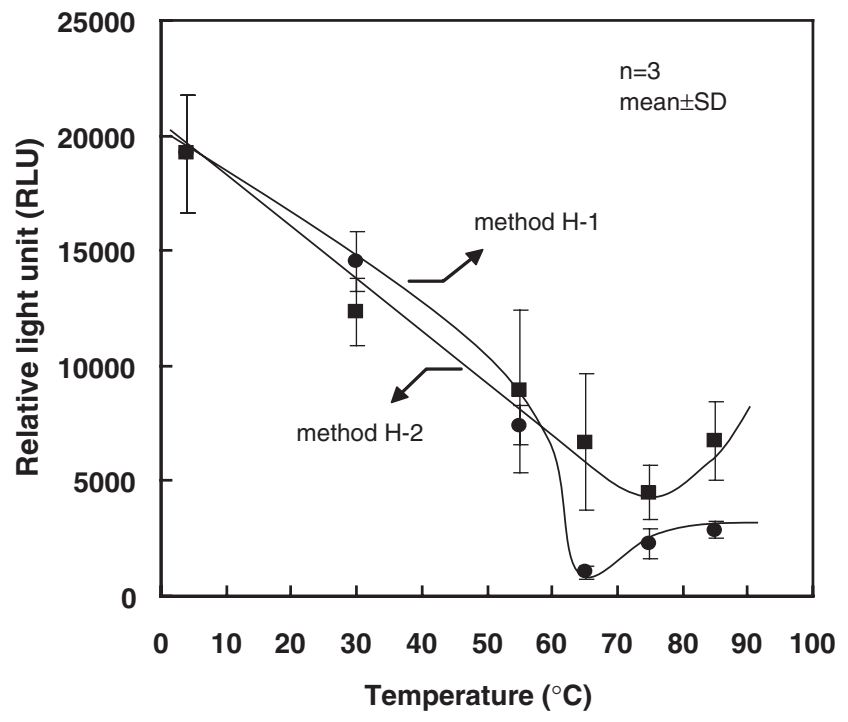

Figure 7. Effects of heat treatment on nonspecific binding behavior. Method H-1 (closed circles): beads were coated with BSA, followed by heat treatment; method H-2 (closed squares), beads were coated with pre-heated BSA in solution. 


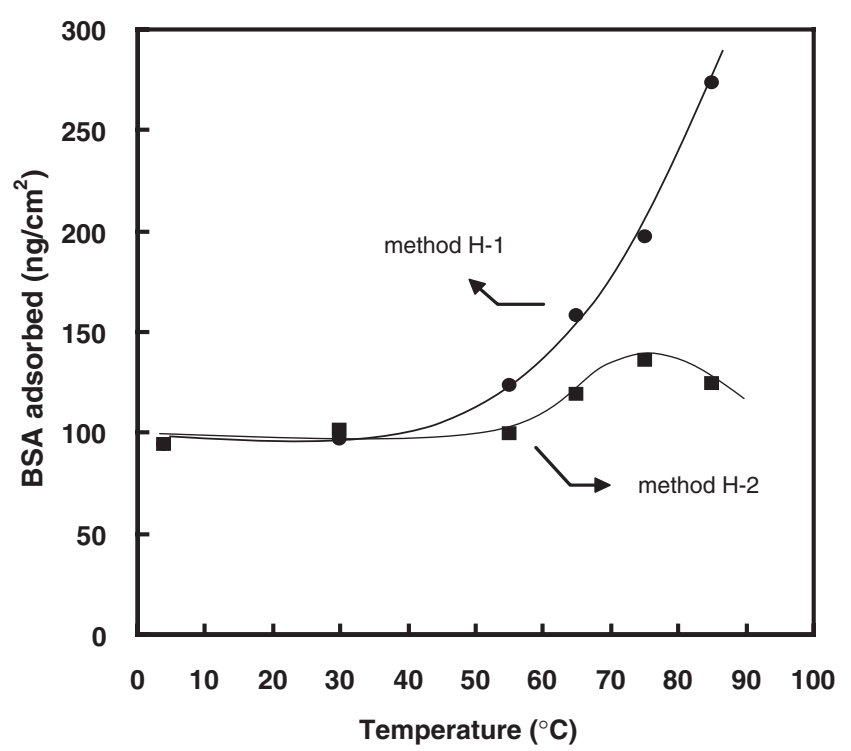

Figure 8. Effects of heat treatment on the amount of bound BSA. Methods H-1 and H-2 are the same as in Figure 7. Data are the mean values of duplicate experiments.

ined; nevertheless, this binding was significantly higher than that on beads prepared by microwave treatment after BSA coating at pH 4.0 (ca. 600 RLU (see Figure 3)). For beads prepared by method H-1, it should be noted that the nonspecific binding reached a minimum at $65^{\circ} \mathrm{C}$ and then increased again above $65^{\circ} \mathrm{C}$, whereas the amount of bound BSA increased more than twice from 55 to $85^{\circ} \mathrm{C}$. The amount of BSA bound at $65^{\circ} \mathrm{C}$ for the method $\mathrm{H}-1$ and at $75^{\circ} \mathrm{C}$ for the method $\mathrm{H}-2$ was 158 and $136 \mathrm{ng} / \mathrm{cm}^{2}$, respectively.

Lin and Koenig measured the heat denaturation of a $5 \%$ concentration of BSA at $\mathrm{pH} 8.0$ by Raman spectrometry, reporting that at $65^{\circ} \mathrm{C}$ the protein secondary structure is affected and associations occur. ${ }^{17}$ Heat denaturation causes the exposure of protein side chain hydrophobic groups on the surface of BSA molecules. The marked increase in the amount of BSA bound at temperatures above $65^{\circ} \mathrm{C}$ is presumably due to further association of the hydrophobic side chains oriented toward the solvent side, starting with hydrophobic groups locating on the surface of BSA molecules being coated onto the beads. From HPLC data (not shown), molecular associations were observed in BSA solution conductively heated at $65^{\circ} \mathrm{C}$, but not in BSA solution subjected to our microwave treatment. The conformational change that takes place during thermal denaturing at $65{ }^{\circ} \mathrm{C}$ is irreversible, and most of the hydrophobic regions in BSA molecules seem to be exposed by this treatment. Therefore, associations between the extremely denatured BSA molecules coated on the bead and those in solution would occur readily. Blocking techniques with BSA at a temperature higher than $65^{\circ} \mathrm{C}$, which lead to an excess amount of bound BSA in the coating layer, may increase nonspecific binding sites on the BSA surface. Moreover, if bare surface spots on a solid phase fixed with heat-unstable ligand proteins are blocked by using method $\mathrm{H}-1$ at a temperature higher than $65^{\circ} \mathrm{C}$, the conductive heat seriously damages the activity of the ligand proteins. By contrast, microwave denaturing should result in an extensively reversible alteration in solution. Consequently, the microwavedenatured BSA molecules coated on the bead are not considered to associate with those in solution, resulting in lower nonspecific binding than that obtained by the conductive heating method. In addition, a further advantage of our microwave treatment is that the microwave irradiation does not reduce the binding activities of heat-unstable biomolecules such as streptavidin, enzyme, and immunoactive compounds (data not shown).

\section{Speculated Processes in Protein-repellant Capacity} Enhancement with Microwave Irradiation

We speculated a model of microwave denaturation processes in coated BSA molecules on the basis of our AFM data and the behavior of water molecules bound to protein that had been reported. ${ }^{8}$ The enhancement of protein resistance at the surface of BSA molecules coated on beads is thought to be accompanied by the dissociation of bound water, followed by protein molecular associations. The predicted processes in protein-repellant capacity enhancement for the BSA-attached surface caused by microwave treatment are schematically shown in Figure 9. The main event, the widespread association between markedly-expanded bound BSA molecules, are thought to be triggered by the dissociation of bound water. The interface of BSA film is inferred to be stabilized by the resultant meshwork formation on the bead. The formation of the protein-resistant layer is likely to be completed by the adsorption of new BSA from the protein solution onto bare spots on the bead surface during the incubation process.

The microwave-treated BSA films on the bead surface were stable under the washing condition of $0.1 \mathrm{M}$ sodium chloride solution containing $0.044 \%$ Tween 20 and $0.011 \%$ Triton X-100 (see Experimental part), whereas a slight amount of BSA coated to the bead without microwave treatment were detached from the bead by this washing (data not shown). This suggests that the BSA films are stabilized by their multipoint attachment to the bead surface, resulting from widespread associations of expanded BSA molecules. The stability of the BSA films after microwave treatment is considered to depend on the nature of binding between the protein and the solid-phase material. 

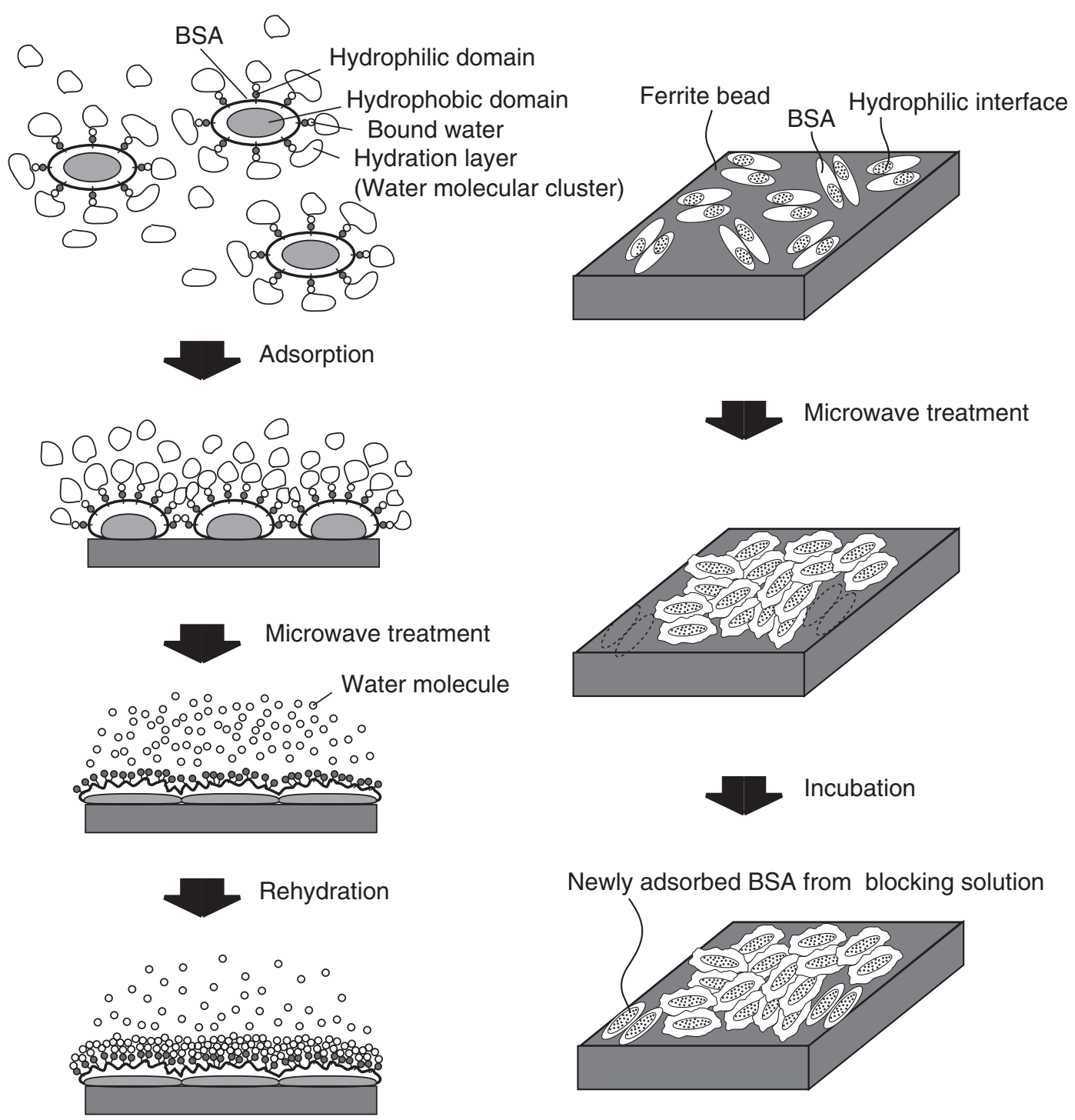

Figure 9. Schematic illustrations for the effects of microwave treatment on the protein-repellant capacity enhancement in BSA molecules bound onto magnetic bead. Shown are the denaturation mechanism, which is coupled to water molecules, at the BSA molecular level (left) and the change in the polymer surface coated with BSA molecules (right).

Physically attached proteins on the solid phase that are closely located to each other may lead to easy association via hydrophobic interactions. Surfaces with low protein adsorption are therefore unlikely to result in adequate protein-repellant capacity enhancement, even with our microwave treatment.

Various kinds of protein treated by microwave irradiation show intrinsic protein-repellant capacity (data not shown). Solid supports for immunoassays generally have both ligands and blocking proteins on their surfaces. For ligand molecular surfaces that are highly hydrophobic and exhibit low protein-repellant capacity with microwave treatment, nonspecific binding may dominantly occur in the hydrophobic regions of the ligand proteins. To circumvent this problem, other reaction medium components, such as surfactants or other proteins, should be examined.

\section{CONCLUSIONS}

We have introduced a new preparation technique for obtaining solid-phase material surfaces showing high protein resistance. Microwave irradiation is a powerful modification tool that can enhance proteinrepellant capacity at protein-coated surfaces mildly in a very short time. To our knowledge, this work is the first in which microwave-treated proteins have been used as blocking agents for solid supports and the degree of protein resistance caused by microwave irradiation has been assessed in a quantitative manner. Magnetic beads supporting microwave-modified proteins were found to give rise to a dramatic reduction in the nonspecific binding of ALP-IgG as compared with those supporting native proteins. Furthermore, the protein-repellant capacity level achieved with mi- 
crowave irradiation was significantly higher than that achieved with conductive heating. Our methodology should be widely applicable to analytical solid supports used in many industrial fields such as medicine, biology, chemistry, and environmental sciences. Future improvements in both assay sensitivity and sample recovery resulting from a reduction in nonspecific binding are expected to be achieved by adapting our microwave treatment to solid-phase preparations used, for example, for immunoassay and liquid chromatography.

Acknowledgment. We would like to express our sincere appreciation to Dr. Hiroshi Maeda, an emeritus professor of Kyushu University, for providing useful suggestions.

\section{REFERENCES}

1. E. Ishikawa, S. Hashida, T. Kohno, and K. Hirota, Clin. Chim. Acta, 194, 51 (1990).

2. J. E. Butler, Methods Enzymol., 73, 482 (1981).

3. S. Yoshitake, M. Imagawa, E. Ishikawa, Y. Niitsu, I. Urushizaki, M. Nishiura, R. Kanazawa, H. Kurosaki, S. Tachibana, N. Nakazawa, and H. Ogawa, J. Biochem., 92, 1413 (1982).

4. N. Miura, N. Asaka, N. Shinyashiki, and S. Mashimo,
Biopolymers, 34, 357 (1994).

5. H. Bohr and J. Bohr, Phys. Rev. E, 61, 4310 (2000).

6. C. Y. Wu, S. T. Chen, S. H. Chiou, and K. T. Wang, J. Protein Chem., 11, 45 (1992).

7. A. Morales-Rubio, C. J. Salvador, and M. de la Guardia, Microchem. J., 47, 270 (1993).

8. A. Higo and M. Shimazaki, J. Home Econ. Jpn., 35 (11), 778 (1984).

9. L. D. Gapochka, M. G. Gapochka, A. F. Korolyov, A. V. Roshchin, A. P. Sukhorukov, N. N. Sysoev, and I. V. Timoshkin, Crit. Rev. Biomed. Eng., 28, No. 5-6, 40 (2000).

10. P. K. Smith, R. I. Krohn, G. T. Hermanson, A. K. Mallia, F. H. Gartner, M. D. Provenzano, E. K. Fujimoto, N. M. Goeke, B. J. Olson, and D. C. Klenk, Anal. Biochem., 150, 76 (1985).

11. I. Bronstein, B. Edwards, and J. C. Voyta, J. Biolumin. Chemilumin., 4, 99 (1989).

12. T. Peters, Jr., "All about Albumin," Academic Press, San Diego, CA, 1996.

13. P. Bagchi and S. M. Birnbaum, J. Colloid Interface Sci., 83, 460 (1981).

14. H. Shirahama and T. Suzawa, J. Colloid Interface Sci., 104, 416 (1985).

15. N. B. Holland and R. E. Marchant, J. Biomed. Mater. Res., 51, 307 (2000).

16. T. Matsumoto and H. Inoue, J. Colloid Interface Sci., 160, 105 (1993).

17. V. J. C. Lin and J. L. Koenig, Biopolymers, 15, 203 (1976). 